\title{
Tethered cord syndrome: surgical outcome of 43 cases and review of literatures
}

\author{
Wael Elmesallamy ${ }^{*}$ (D), Atef AbdAlwanis and Sami Mohamed
}

\begin{abstract}
Objective: To evaluate the surgical treatment of tethered cord syndrome (TCS), a prospective analysis of 43 patients operated at Neurosurgery Department Zagazig University hospitals from May 2013 to January 2017 with 1 year follow-up had been done.

Patients and methods: Adult and children patients with tethered cord syndrome subjected to microscopic surgeries for release of cord and nerves tethering with exclusion of primary repair of meningiomyelocele, paraplegic patients, hydrocephalic patients, and ages below 2 years old. Magnetic resonance imaging (MRI) of the spine was done for all patients and urodynamic studies for patients more than 6 years old preoperative and postoperative after 1 year of surgery.
\end{abstract}

Results: Ten patients were adults $>18$ years old and male to female ratio was about 2:1. All patients presented with multiple clinical manifestations which either improved or stable during follow-up after surgery. Controllable complications occurred: cerebrospinal fluid (CSF) leak in 18.6\% and wound infection in 4.7\%. Urodynamic studies improved in $73 \%$ of patients after surgery and children showed significant improvement in all symptoms except back pain than adult patients.

Conclusion: Microscopic surgery is of value for patients suffering tethered cord syndrome with low risk of complications.

Keywords: Tethered cord, Urodynamic study, Microscopic surgery

\section{Introduction}

Tethered cord syndrome (TCS) is a stretch-induced functional disorder of the spinal cord with its caudal part anchored by an inelastic structure. The accepted cause of TCS is spinal cord traction, which leads to anatomic and metabolic disorders that are responsible for the clinical presentation. Fixation of the spinal cord can occur congenitally (primary TCS) or in association with other intra-spinal pathologies or postoperative scarring (secondary TCS). Most cases are related to spinal dysraphism [1]. The age at presentation of TCS ranges from early childhood to the $80 \mathrm{~s}$. The symptoms related to a congenital tethered cord occur most commonly in childhood, but in many patients, the diagnosis is not established until adulthood. The presentation may also differ according to the underlying pathology, with back and leg pain, cutaneous signs, orthopedic deformities, muscle

\footnotetext{
* Correspondence: waelmesallamy@gmail.com

Neurosurgery Department, Zagazig Faculty of Medicine, Zagazig, Egypt
}

weakness, urinary dysfunction, and neurological deficits being the most common. Other manifestations include gait deterioration, foot deformities, progressive scoliosis, and sphincter incontinence. Young children may have skeletal growth deformities, such as a leg length discrepancy. Adolescent or young adult patients often complain of unexplained long-term back pain [2].

Decisions about treatment for tethered cord syndrome are complicated. Once the diagnosis established or when there is an established likelihood that tethered cord syndrome is evolving, the neurosurgeon is required to choose among treatment alternatives that will help patients to maintain normal lives while minimizing surgical risks [1].

In this work, we presented a study of 43 patients with tethered cord syndrome to evaluate the clinical presentation, imaging findings of such cases, and results of surgical treatment. 


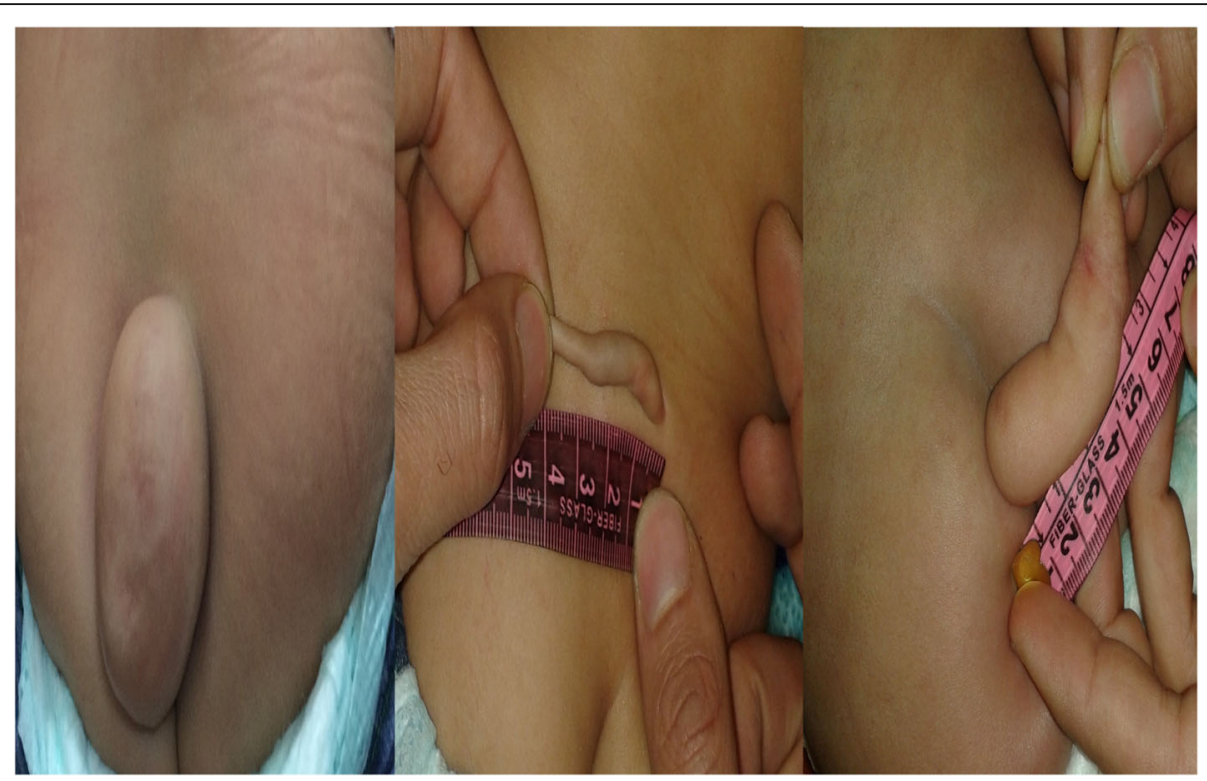

Fig. 1 Different human tails associated with tethered cord

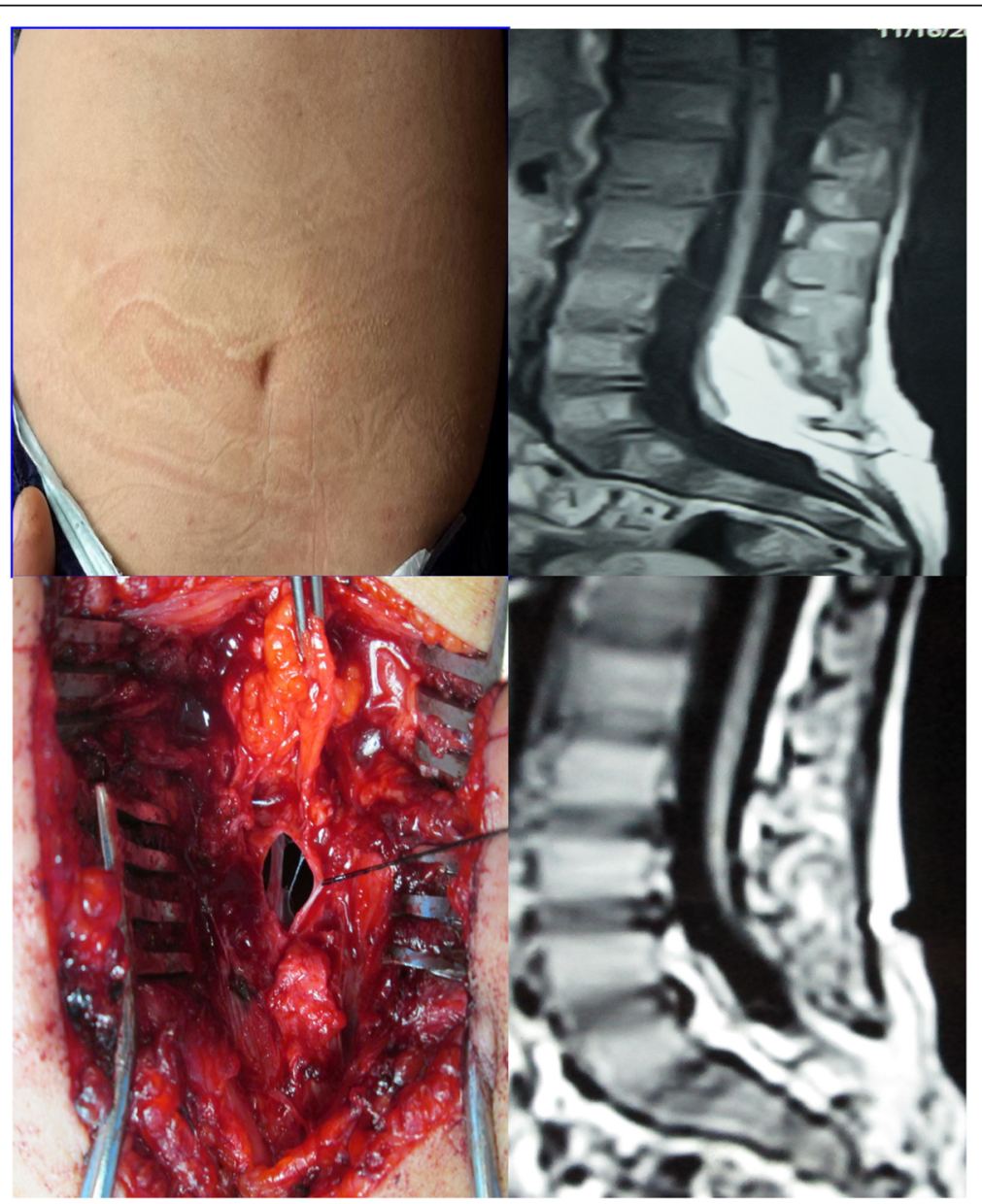

Fig. 2 Male patient 3 years old. Skin dimple image, T1 MRI with cord tethering by lipoma extending intradural, and conus level at the fifth lumber vertebra. Intraoperative image showing total removal of the lipoma and after 1 year follow-up T1 MRI with conus level at lumber 3-4 disc and no lipoma 


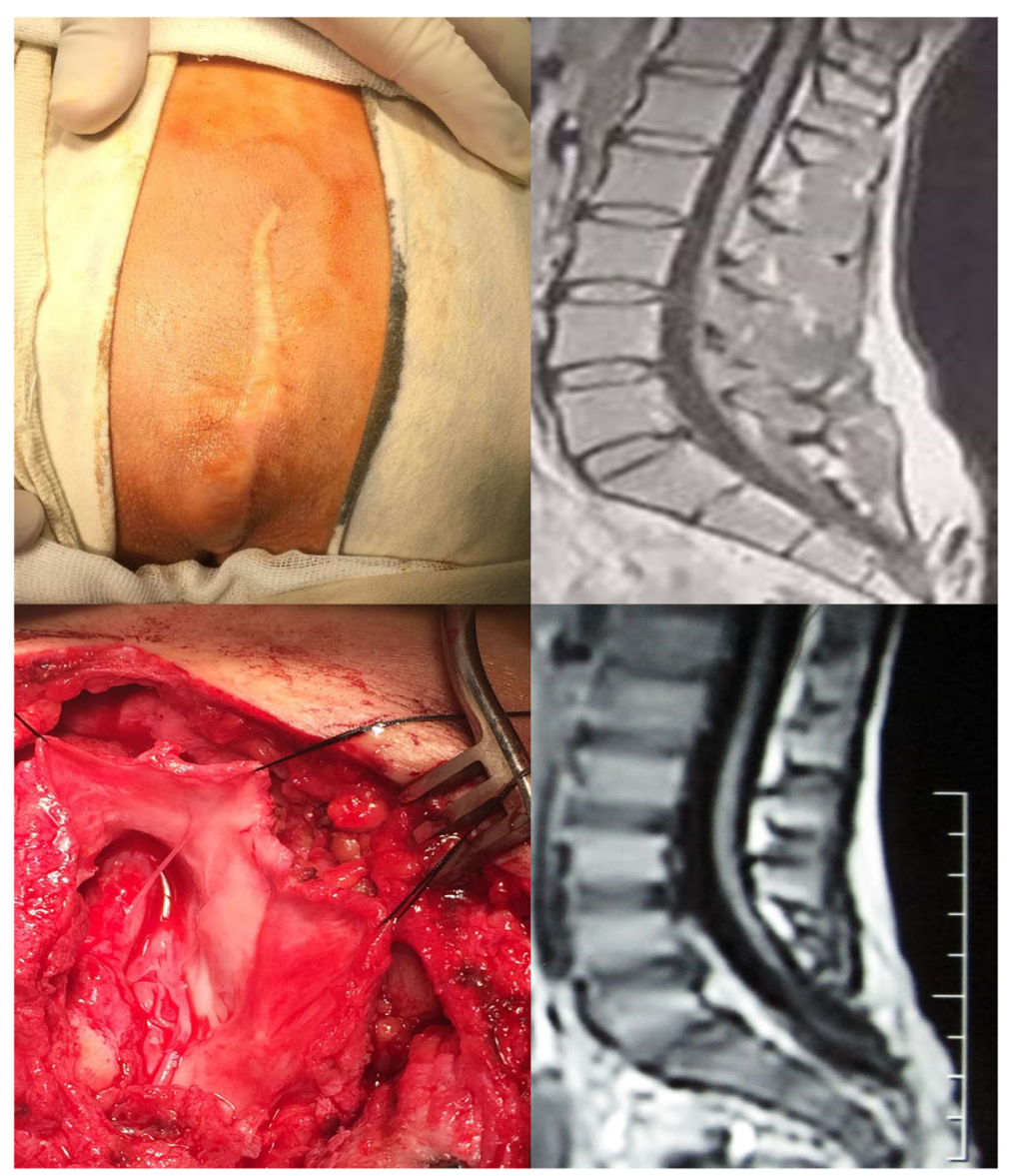

Fig. 3 Male patient 23 years old with recurrent cord tethering. T1MRI preoperative conus location at the second sacral vertebra, intraoperative imaging after cord release, and 1 year postoperative T1MRI with conus level between the fifth lumbar and first sacral vertebra

\section{Patients and methods}

Forty-three patients with tethered cord syndrome, 29 males and 14 females with ages from 2 to 23 years old, were operated at Neurosurgery Department Zagazig University Hospital from May 2013 to January 2017 after approval from the Zagazig University Institutional review board (Zu-IRB). On admission, a written consent was taken for the procedure of untethering under general anesthesia by microscopic surgery. All patients were evaluated for general and neurological condition by clinical, laboratory, and imaging examination. Preoperative MRI of the spine was done for all patients, and urodynamic studies were done for patients more than 6 years old. Clinical evaluation had been done till hospital discharge and then after 3, 6, and 12 months. Urodynamic studies and MRI of the spine repeated after 1 year of surgery. All patients were subjected to microscopic surgeries for untethering under general anesthesia for releasing tethering elements and repair of the thecal sac. Patients included in this study were diagnosed with tethered cord syndrome clinically and by imaging with exclusion of primary repair of meningiomyelocele, paraplegic patients, hydrocephalic patients, and ages below 2 years old. Data collected throughout preoperative and postoperative examination and investigations were analyzed and submitted to statistical procedures using statistical packages for social science (SPSS) version 20. $P$ value was set at $<0.05$ for significant results (Figs. 1, 2, 3, 4, and 5).

\section{Results}

Patients of this study were 29 males and 14 females with ratio about 2:1, and the youngest was 2 years old and the oldest was 23 years old with a mean age of 9 years (Tables 1 and 2). Table 3 shows the clinical presentation of these patients; back lump was the commonest back sign. Clinical analysis of those patients especially below 6 years old must be taken with consideration of normal physiological and mental development as normal urine control can be considered at age 5 years, stool control at age 4 years, and mental pain/parathesia differentiation at 6 years old. Imaging and urodynamic studies of our patients (Table 4) show spina bifida in $33 / 43$ (77\%) patients, lipoma in $20 / 43$ (71\%) patients, and conus location at L5 in 35\% of the patients. Urodynamic studies show neurogenic bladder abnormalities in all examined patients (15/15, 100\%). Microscopic 


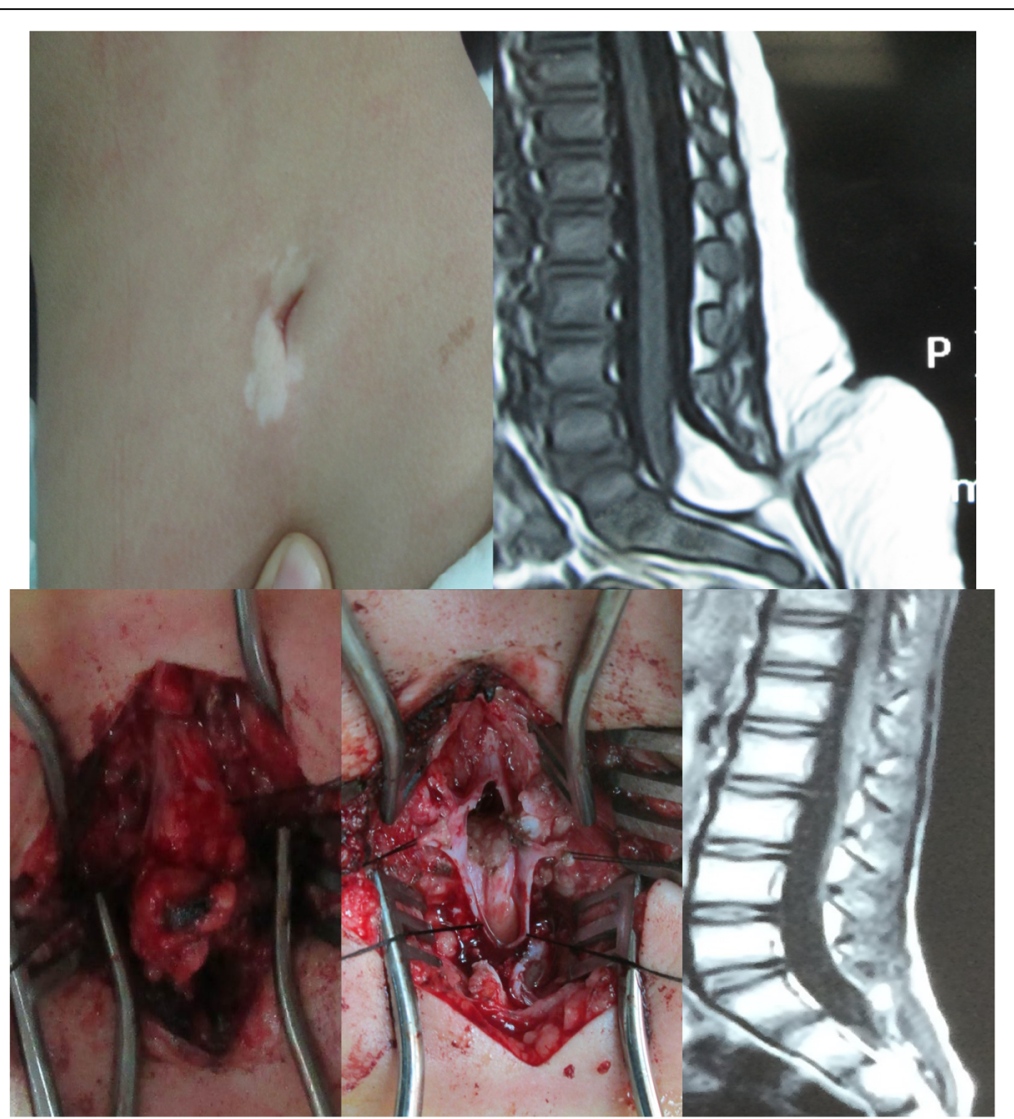

Fig. 4 Subtotal resection of intradural lipoma in 6 years old male child with skin dimple. Preoperative T1MRI, intraoperative images, and 1 year postoperative T1MRI

untethering was done for all patients under general anesthesia with operative findings in Table 5 and surgical procedures in Table 6. Intraoperative adhesions were found in $36 / 43(84 \%)$ patients and released in all patients. Thickened filum terminale was found in $28 / 43(65 \%)$ patients and sectioned in all patients. Postoperative complications were cerebrospinal fluid (CSF) leak in seven patients, of them two patients needed secondary sutures and two patients suffered wound infection and treated conservatively (Table 7). After 1 year follow-up, there were significant improvements in children compared to adults regarding parathesia, lower limb weakness, urinary abnormalities, and bowel abnormalities (Table 8). Tables 9 and 10 show the significant role of filum sectioning and absence of lipoma in clinical improvement in those patients. Urodynamic study improvements were noted in $11 / 15(73 \%)$ patients, lipoma size decreased in all affected patients, and conus location changed in only $7 \%$ patients at 1 year follow-up (Table 11). Demonstrative cases shown in (Figs. 1, 2, 3, 4, and 5).

\section{Discussion}

Most series on tethered cord syndrome showed female predominance $[3,4]$, while our study showed male predominance $(67 \%)$.
Tethered cord syndrome is mostly noted in children. There were 23 adult patients versus 50 children with tethered cord treated in Sofuoglu et al. [3] report. In our study, there were 33 children and the 10 adult patients.

Clinical manifestations of TCS differ among patients especially children and adults. The symptoms and signs may be noted since birth or appear later on with body growth as the spines elongate and stretch-induced functional disorders of the spinal cord and roots occur. Clinical manifestations of children in this study were back lump in $70 \%$, skin dimple in $9 \%$, back pain and parathesia from the age of 6 years old in $100 \%$ and $67 \%$ respectively, lower limb weakness in $61 \%$, urine abnormalities from the of age 5 years in $75 \%$, and bowel abnormalities from the age of 4 years in $65 \%$. The study of Yelikbayev and Tutayeva [5] on 30 children aged 2-18 years reported weakness in $87 \%$, impaired functions of pelvic organs in $90 \%$, and skin manifestations in $77 \%$. Khoshhal et al. [2] study on 35 patients aged 2 months to 11 years found that the most frequent dysraphism was lipomeningomylocele $(34.3 \%)$ followed by myelomeningocele $(22.8 \%)$ and dermal sinus (14.3\%). Back lump was presented in $65.7 \%$, and neurological impairment in $68.4 \%$ of 2 years or older. 


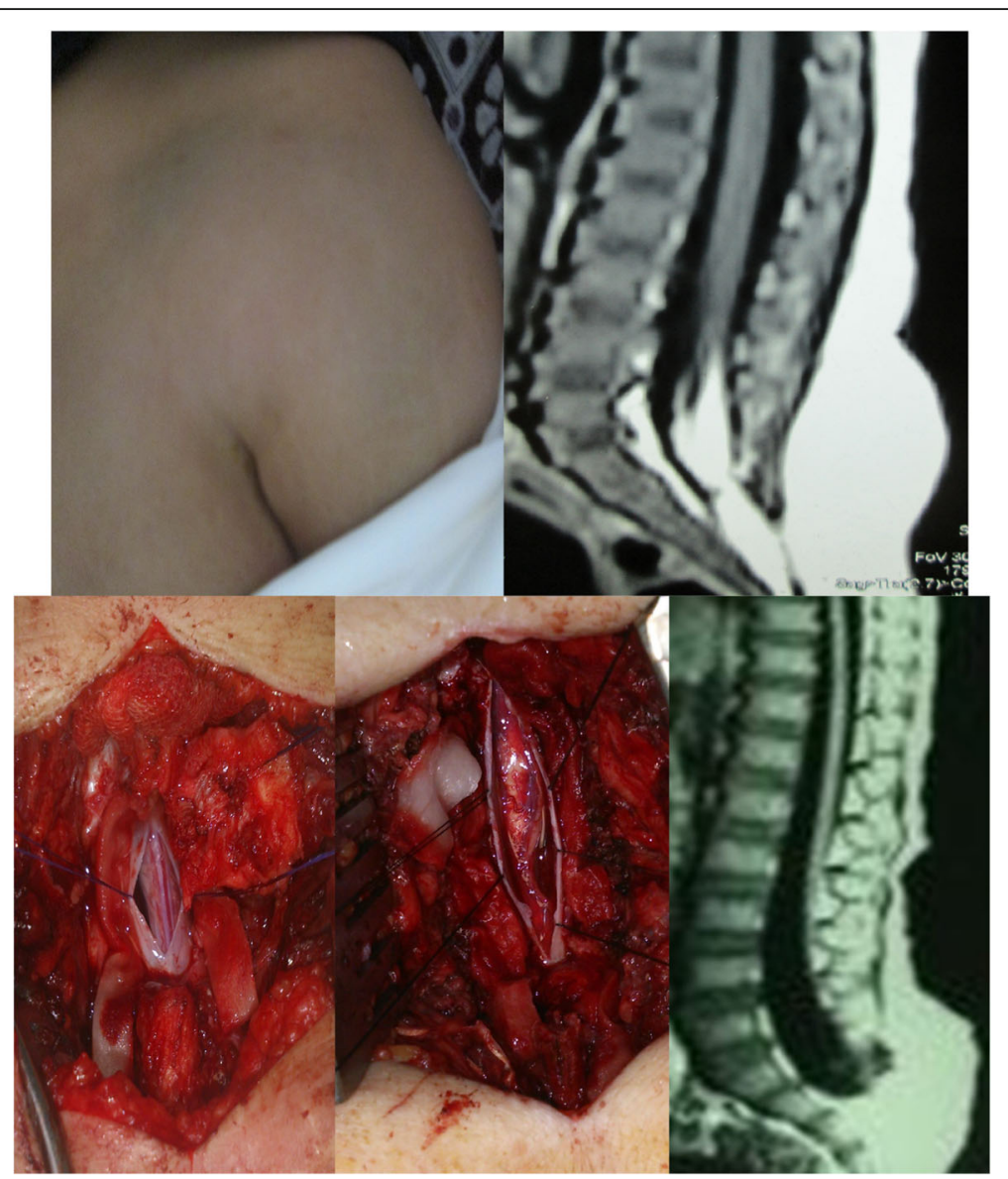

Fig. 5 Total resection of intradural lipoma in 3 years old female child. Preoperative T1MRI, intraoperative images, and T1MRI 1 year postoperative

Adult patients in this study presented with urine abnormalities in $100 \%$, bowel abnormalities in $80 \%$, back pain in $80 \%$, lower limbs weakness in $60 \%$, and back lump in $50 \%$ of the patients. Gao et al. [6] study on 82 adult tethered cord patients found low back pain in $83 \%$, weakness in $71 \%$, sensory dysfunction in $54 \%$, and defecation dysfunction in 50\%. Sofuoglu et al. [3] reported clinical manifestations of adult tethered cord as $65.2 \%$ back pain, $52.2 \%$ bladder dysfunction, $17.4 \%$ fecal incontinence, $52.2 \%$ weakness, $21.7 \%$ numbness, and $61 \%$ back swelling.

MRI, plain X-ray of the spine, and urodynamic studies are of great value for diagnosis and management of

Table 1 Demographic data

\begin{tabular}{llll}
\hline Parameters & No. & $\%$ & $P$ \\
\hline Age & & & \\
2-18 years & 33 & 77 & 0.01 \\
$>$ 18 years & 10 & 23 & \\
Sex & & & 0.03 \\
Male & 29 & 67 & \\
Female & 14 & 33 & \\
\hline
\end{tabular}

Table 2 Clinical data

\begin{tabular}{|c|c|c|c|c|c|}
\hline \multirow[t]{2}{*}{ Parameters } & \multicolumn{2}{|c|}{$\begin{array}{l}\text { Children ( } 2- \\
18 \text { years) }\end{array}$} & \multicolumn{2}{|c|}{$\begin{array}{l}\text { Adults (> } 18 \\
\text { years) }\end{array}$} & \multirow[t]{2}{*}{$P$} \\
\hline & No. & $\%$ & No. & $\%$ & \\
\hline Back pain (age $>6$ years & $15 / 15$ & 100 & $8 / 10$ & 80 & 0.07 \\
\hline Parathesia (age $>6$ years) & $10 / 15$ & 67 & $10 / 10$ & 100 & 0.03 \\
\hline Weakness in lower limbs & $20 / 33$ & 61 & $6 / 10$ & 60 & 0.87 \\
\hline Urinary abnormality (age $>5$ years) & $15 / 20$ & 75 & $10 / 10$ & 100 & 0.058 \\
\hline Bowel abnormality (age $>4$ years) & $15 / 23$ & 65 & $8 / 10$ & 80 & 0.05 \\
\hline \multicolumn{6}{|l|}{ Back signs } \\
\hline Lump & $23 / 33$ & 70 & $5 / 10$ & 50 & 0.03 \\
\hline Scar of pervious surgery & $5 / 33$ & 15 & $2 / 10$ & 20 & 0.07 \\
\hline Dimple & $3 / 33$ & 9 & $0 / 10$ & 0 & 0.001 \\
\hline Hair tuft & $2 / 33$ & 6 & $1 / 10$ & 10 & 0.06 \\
\hline Hemangioma & $2 / 33$ & 6 & $1 / 10$ & 10 & 0.06 \\
\hline Normal skin & $21 / 33$ & 64 & $6 / 10$ & 60 & 0.08 \\
\hline
\end{tabular}


Table 3 Back lump characters

\begin{tabular}{llll}
\hline Parameter & No & $\%$ & $P$ \\
\hline Shape & 13 & 46 & 0.03 \\
Round & 11 & 39 & \\
Oval & 4 & 14 & \\
Tail & & & 0.01 \\
Site & 8 & 29 & \\
Lumber & 15 & 54 & \\
Lumbosacral & 5 & 18 & 0.005 \\
Sacral & & & \\
Skin & 22 & 79 & 0.007 \\
Normal & 6 & 21 & \\
Abnormal & & & \\
Content & 20 & 71 & \\
Lipoma & 8 & & \\
CSF & & & \\
\hline
\end{tabular}

tethered cord syndrome. We found spina bifida in 33 (77\%) patients, lipoma in $20(47 \%)$ patients, dermoid in 3 (7\%) patients, conus level at L5 in 15 (35\%) patients, and urodynamic studies were impaired in all study cases, mostly hyper-reflexic bladder (67\%). Sofuoglu et al. [3] noted in their study on 23 adult patients the commonest conus level was L5 (34.8\%), lipoma in 37\%, and dermal sinus in $21.7 \%$. Gupta et al. [7] mentioned that the most frequent MRI finding was a low lying spinal cord with intradural and/or extradural lipoma. Yelikbayev and Tutayeva [5] study on children noted hyper-reflexic bladder is often marked, and they considered the tethered cord syndrome as the cause of neurogenic hyper-reflexic bladder even the conus at normal level

Table 4 Imaging and urodynamic studies

\begin{tabular}{llll}
\hline Parameters & No & $\%$ & $P$ \\
\hline Spina bifida & 33 & 77 & 0.01 \\
Lipoma & 20 & 47 & \\
Dermoid & 3 & 7 & \\
Conus location & 5 & & \\
L3 & 15 & 12 & 0.04 \\
L5 & 10 & 35 & \\
S1 & 13 & 23 & \\
$\quad$ S2-3 & & 30 & \\
Urodynamic abnormality & $10 / 15$ & 67 & 0.01 \\
Hyper-reflexia & $3 / 15$ & 20 & \\
Dys-synergy & $3 / 15$ & 20 & \\
Decrease sensation & $3 / 15$ & 20 & \\
Decrease compliance & $2 / 15$ & 13 & \\
Decrease contractility & & & \\
\hline
\end{tabular}

Table 5 Surgical findings

\begin{tabular}{lll}
\hline Parameter & No & $\%$ \\
\hline Dura & 12 & 28 \\
Intact & 36 & 84 \\
Adhesions & 31 & 72 \\
Defect & & \\
Cord & 16 & 37 \\
Intact & 14 & 33 \\
Split & 13 & 30 \\
Compressed & & \\
Roots & 15 & 35 \\
Intact & 12 & 28 \\
Adhesions & 16 & 37 \\
Lipomatous amalgamation & & \\
Filum & 28 & 65 \\
$\quad$ Thickened & 8 & 19 \\
Midline & 20 & 57 \\
Displaced & 15 & 35 \\
Unidentified & & \\
\hline
\end{tabular}

without filum terminalis changes. In $18-54 \%$ of TCS patients, the conus lies at normal level, and diagnosis by dynamic MRI of the spine shows effort-induced symptoms $[8,9]$, but this not found in our study. Also, conus level varied between studies as Valentini et al. [10] reported L2-L3 level in 50\% of patients.

Microscopical treatment was done for all patients dealing of the offending pathologies.

Cerebrospinal fluid leak occurred in eight patients (19\%), two of them needed 2ry sutures. Wound infection occurred in two cases and 5\% were treated conservatively. Duz et al. [11] reported 5\% CSF leak, and no

Table 6 Surgical procedure

\begin{tabular}{lll}
\hline Parameters & No & $\%$ \\
\hline Spine & 8 & 19 \\
Laminoplasty & 22 & 51 \\
Laminectomy & 13 & 30 \\
No widening & & \\
Lipoma & $4 / 20$ & 20 \\
$\quad$ Total removal & $16 / 20$ & 80 \\
Subtotal & $3 / 3$ & 100 \\
Dermoid (total removal) & & \\
Filum & 28 & 65 \\
$\quad$ Sectioned & 15 & 35 \\
$\quad$ Not & $36 / 36$ & 100 \\
Dural adhesion release & 43 & 100 \\
Skin primary repair &
\end{tabular}


Table 7 Postoperative complications

\begin{tabular}{|c|c|c|c|c|c|c|}
\hline \multirow[t]{2}{*}{ Parameters } & \multicolumn{2}{|c|}{$\begin{array}{l}2-18 \\
\text { years }\end{array}$} & \multicolumn{2}{|c|}{$\begin{array}{l}>18 \\
\text { years }\end{array}$} & \multirow[t]{2}{*}{$P$} & \multirow[t]{2}{*}{ Management } \\
\hline & & $\%$ & $\overline{\text { No. }}$ & $\%$ & & \\
\hline CSF leak & 7 & 21 & 1 & 1 & 0.03 & $\begin{array}{l}6 \text { cases conservative } 2 \text { cases } 2 \text { ry } \\
\text { sutures }\end{array}$ \\
\hline $\begin{array}{l}\text { Wound } \\
\text { infection }\end{array}$ & 2 & 6 & 0 & 0 & & Conservative \\
\hline
\end{tabular}

infections in 22 patients. Sofuoglu et al. [3] reported CSF leak in three patients and wound infection in three patients (13\%). Rajpal et al. [12] reported 3/61 patients suffered wound infection, one patient suffered CSF leak, two patients suffered pseudomeningocele, and one patient suffered acute respiratory distress syndrome. Iskandar et al [13] reported one CSF leak and five pseudomeningocele in their study on 34 patients.

Clinical improvement 1 year after surgery in our study showed back pain improvement in $60 \%$ of children and $75 \%$ of adults, parathesia improved in $60 \%$ of children and $30 \%$ of adults, weakness improved in $40 \%$ of children and $17 \%$ of adults, urine abnormalities improved in $60 \%$ of children and $30 \%$ of adults, and bowel abnormalities improved in $47 \%$ of children and $25 \%$ of adult patients. Children in our study showed significant improvement regarding all symptoms except back pain in comparison with adults. Intraoperative filum sectioning showed significant improvement of patient symptoms except back pain, and absence of lipoma showed significant improvement in weakness. Review of literatures suggests that the tethered cord syndrome reversible symptoms are due to metabolic derangement and alterations in oxidative metabolism. Persistent symptoms may vary depending on severity and duration at presentation [8]. Iskandar et al. [13] found improvement in adults, $81.5 \%$ back pain, $43.1 \%$ motor or sensory dysfunctions, and $61.1 \%$ bowel and bladder disturbance. Sofuoglu et al. [3] reported 50\% improvement in back pain, $66.7 \%$ motor weakness improvement, and $75 \%$ bladder and bowel improvement in adults. Lee et al. [1] found improvements in $78 \%$ back pain, $83 \%$ leg pain, $64 \%$ motor weakness, and 50\% urological abnormalities. Duz et al. [11]

Table 8 Clinical improvement after 1 year of surgery

\begin{tabular}{|c|c|c|c|c|c|}
\hline \multirow[t]{2}{*}{ Parameters } & \multicolumn{2}{|c|}{$2-18$ years } & \multicolumn{2}{|c|}{$>18$ years } & \multirow[t]{2}{*}{$P$} \\
\hline & $\overline{\text { No }}$ & $\%$ & $\overline{N o}$ & $\%$ & \\
\hline Back pain & 9/15 & 60 & $6 / 8$ & 75 & 0.05 \\
\hline Parathesia & $6 / 10$ & 60 & $3 / 10$ & 30 & 0.01 \\
\hline Weakness & $8 / 20$ & 40 & $1 / 6$ & 17 & 0.003 \\
\hline Urinary abnormalities & $9 / 15$ & 60 & $3 / 10$ & 30 & 0.01 \\
\hline Bowel abnormalities & $7 / 5$ & 47 & $2 / 8$ & 25 & 0.03 \\
\hline
\end{tabular}

Table 9 Role of filum terminal sectioning in improvement

\begin{tabular}{lllllll}
\hline Parameters & \multicolumn{2}{l}{ Sectioned } & & Not & $P$ \\
\cline { 2 - 3 } & No. & $\%$ & & No. & $\%$ & \\
\hline Back pain & $9 / 15$ & 60 & & $6 / 5$ & 67 & 0.5 \\
Parathesia & $8 / 9$ & 89 & & $1 / 9$ & 11 & 0.003 \\
Weakness & $9 / 9$ & 100 & & $0 / 9$ & 0 & 0.0001 \\
Urine abnormality & $9 / 12$ & 75 & & $3 / 12$ & 25 & 0.001 \\
Bowel abnormality & $9 / 9$ & 100 & & $0 / 9$ & 0 & 0.0001 \\
\hline
\end{tabular}

reported back pain improvement in $57.1 \%$ and bladder dysfunction in $66.6 \%$, and two patients with fecal incontinence did not improve. Rajpal et al. [12] reported back pain improved in $65 \%$ and bowel/bladder dysfunctions in $62 \%$. Solmaz et al. [14] reported urological improvement in 21 patients (20\%) and back pain improved in all patients on their study on 49 children. In Bowman et al. [15] study on children with myelomeningocele for untethering, the pain improved in $100 \%$, and $70 \%$ showed improvement in lower extremities and $64 \%$ in bladder dysfunctions. Haro et al. [16] reported that adults showed better improvement in neurological and urinary problems than natal or juvenile onset tethered cord syndrome. Seki et al. [17] mentioned that age at surgery is not significantly associated with prognosis. Tethered cord syndrome may have different curative effect after surgery according to the cause. Removal of the thickened filum can get better results [6]. Recurrent surgeries and presence of lipoma had higher incidence of failed detethering [10]. Also, Selden et al. [18] found significant improvement with filum sectioning. These data agree with our results.

Conus location detected by MRI on follow-up found to be on the same location as preoperative MRI in $77 \%$ of the patients in our study, and urodynamic studies showed improvement in $73 \%$ of the studied patients. Postoperative MRI has no role for evaluation of good detethering but only clinical and urodynamic evaluation. Even the presence of lipoma residual is not significantly associated with retethering [19]. Kearns et al. [20] found 44\% improvement

Table 10 Role of lipoma presence in improvement

\begin{tabular}{|c|c|c|c|c|c|}
\hline \multirow[t]{2}{*}{ Parameters } & \multicolumn{2}{|c|}{ Present } & \multicolumn{2}{|c|}{ Not present } & \multirow[t]{2}{*}{$P$} \\
\hline & $\overline{\text { No. }}$ & $\%$ & $\overline{\text { No. }}$ & $\%$ & \\
\hline Back pain & $5 / 12$ & 42 & $7 / 12$ & 58 & 0.05 \\
\hline Parathesia & $4 / 9$ & 44 & $5 / 9$ & 56 & 0.09 \\
\hline Weakness & $3 / 9$ & 33 & $6 / 9$ & 67 & 0.01 \\
\hline Urine abnormality & $4 / 12$ & 33 & $8 / 12$ & 67 & 0.01 \\
\hline Bowel abnormality & $3 / 9$ & 33 & $6 / 9$ & 67 & 0.01 \\
\hline
\end{tabular}


Table $11 \mathrm{MRl}$ and urodynamic studies after 1 year of surgery

\begin{tabular}{llllllll}
\hline Parameters & \multicolumn{2}{l}{ The same } & & \multicolumn{2}{l}{ Changed } & $P$ \\
& No. & $\%$ & & No. & $\%$ & \\
\hline MRI & & & & & & \\
Conus location & $33 / 43$ & 77 & & $10 / 43$ & 23 & 0.001 \\
Lipoma size & $0 / 20$ & 0 & $20 / 20$ & 100 & 0.0001 \\
Urodynamic study & $4 / 15$ & 27 & $11 / 15$ & 73 & 0.001 \\
\hline
\end{tabular}

in urodynamic studies on 34 children after tethered cord repair and mentioned that a review of five series showed improvement in 11.1-54.5\% after untethering, but none of their patients or other studies became urologically normal as the conus and roots were inevitably exposed to some injuries, also documented by [21, 22]. Improvement of urological symptoms or urodynamic finding reported to be $38 \%$ and $100 \%$ respectively by Vernet et al. [23] and Flanigan et al. [24].

\section{Conclusion}

Clinical presentation of tethered cord syndrome differs according to underlying pathology and age of the patients. There were improvements in patient conditions in all studies with few controllable complications. Surgical treatment is beneficial in most patients, and childhood intervention is better than adulthood. Postoperative MRI findings not necessarily correlate with surgical outcome but clinical and urodynamic studies are the best predictors.

\section{Study limitations}

1. The causes of tethered cord syndrome are so much and in need for a bigger number of cases for evaluation.

2. The follow-up evaluation was 1 year only, which is a short period.

\section{Abbreviations}

CSF: Cerebrospinal fluid; MRI: Magnetic resonance imaging; TCS: Tethered cord syndrome

\section{Acknowledgements}

Not applicable.

\section{Funding}

No funding was received for this study.

\section{Availability of data and materials}

All data that support the findings of this study are available from the neurosurgery department Zagazig university hospital. Data are however available from the authors when requested with permission.

\section{Authors' contributions}

WAAE, AKAA, and SHM contributed to the study conception, design, and surgical works. WAAE collected data and drafted the manuscript. All authors read and approved the final manuscript.

\section{Ethics approval and consent to participate}

A written consents were obtained for all patients ( from the patient and from the parent when age below 16 years old ), and the study approved by Zagazig university institutional review board (Zu-IRB) on 15/3/ 2013.

\section{Consent for publication}

A written consents for publication from the patients and from parents when the age below 16 years old were attained.

\section{Competing interests}

The authors declare that they have no competing interests.

\section{Publisher's Note}

Springer Nature remains neutral with regard to jurisdictional claims in published maps and institutional affiliations.

Received: 3 August 2018 Accepted: 6 January 2019

Published online: 25 January 2019

References

1. Lee GY, Paradiso G, Totor CH, Gentili F, Massicotte EM, Fehlings MG. Surgical management of tethered cord syndrome in adults: indications, techniques, and long-term outcome in 60 patients. J Neurosurg Spine. 2006;4(2):123-31.

2. Khoshhal KI, ABOS MWR, Elgamal EA, Salih MAM. Tethered cord syndrome: a study of 35 patients. J Taibah University Med Sci. 2012;7(1):23-8.

3. Sofuoglu OE, Abdullah A, Emel E, Guler B. Management of tethered cord syndrome in adults: experience of 23 cases. Turk Neurosurg. 2017;27(2):226-36.

4. Klekamp J. Tethered cord syndrome in adults. J Neurosurg Spine. 2011;15: 258-70.

5. Yelikbayev GM, Tutayeva AA. Clinical manifestation of a tethered cord syndrome at children, and research methods for early diagnosis of disease. Biomed Pharmacol J. 2015;8(2):597-601

6. Gao J, Kong X, Li Z, Wang T, Li Y. Surgical treatment on adult tethered cord syndrome. A retrospective study. Medicine. 2017;96(32):e7808.

7. Gupta SK, Khosla VK, Sharma BS, Mathuriya SN, Pathak A, Tewari MK. Tethered cord syndrome in adults. Surg Neurol. 1999;52(4):362-70.

8. Yamada S, Won DJ, Siddiqi J, Yamada SM. Tethered cord syndrome: overview of diagnosis, and treatment. Neurol Res. 2004;26:719-21.

9. Warder DE, Oakes WJ. Tethered cord syndrome: the low lying, and normally positioned conus. Neurosurg. 1994;34:597-600.

10. Valentini LG, Selvaggio G, Visintini S, Erbetta A, Scaioli V, Solero CL. Tethered cord: natural history, surgical outcome, and risk for Chiari malformation 1 (CM1). Neurol Sci. 2011;32(3):353-6.

11. Duz B, Gocmen S, Secer HI, Basal S, Gonul E. Tethered cord syndrome in adulthood. J Spinal Cord Med. 2008;31(3):272-8.

12. Rajpal S, Tubbs RS, George T, Oakes WJ, Fuchs HE, Hadley MN, Iskander BJ. Tethered cord due to spina bifida occulta presenting in adulthood: a tricenter review of 61 patients. J Neurosurg Spine. 2007:6(3):210-5.

13. Iskandar BJ, Flumer BB, Hadley MN, Oakes WJ. Congenital tethered spinal cord syndrome in adults. Neurosurg Focus. 2001;10(1):e71-5.

14. Solmaz I, Izci Y, Albayrak B, Cetinalp E, Kural C, Sengul G, Gocmez C, Pausal S, Tuzun Y. Tethered cord syndrome in childhood: special emphasis on the surgical technique, and review of the literature with our experience. Turk Neurosurg. 2011;21(4):516-21.

15. Bowman RM, Mohan A, Itot J, Mclone DJ. Tethered cord release: a long-term study in114 patients: clinical article. J Neurosurg Pediatr. 2009;3(3):181-7.

16. Haro H, Komori H, Okawa A, Kawabata S, Shinomiya K. Long-term outcome of surgical treatment for tethered cord syndrome. J Spinal Disord Tech. 2004:17(1):16-20.

17. Seki T, Hida K, Yano S, Sasamori T, Hamauch S, Koyanagi I, Houkin K. Surgical outcome of children, and adolescents with tethered cord syndrome. Asian Spine J. 2016;10(5):940-4.

18. Selden NR, Nixon RR, Skoog SR, Lashley DB. Minimal tethered cord syndrome associated with thickening of the terminal filum. J Neurosurg. 2006;105(3):214-8.

19. Schoenmakers MA, Gooskens RH, Gulmans VA, Hanlo PW, Vandertop WP, Uiterwaal CS, Helders PJ. Long-term outcome of neurosurgical untethering on neurosegmental motor and ambulation levels. Dev Med Child Neurol. 2003;45: 551-5.

20. Kearns JT, Esposito D, Dooley B, Frim D, Guandeti MS. Urodynamic studies in spinal cord tethering. Childs Nerv Syst. 2013;29:1589-600. 
21. Gross AJ, Michael T, Godeman F, Weigel K, Huland H. Urological finding in patients with neurosurgically treated tethered spinal cord. J Urol. 1993;149:1510-1.

22. Paradiso G, Lee GY, Sarjeant R, Fehlings MG. Multi-modality neurophysiological monitoring during surgery for adult tethered cord syndrome. J Clin Neurosci. 2005;12(93):935-7.

23. Vernet O, Farmer JP, Houle AM, Montes JL. Impact of urodynamic studies on the surgical management of the spinal cord tethering. J Neurosurg. 1996;85:555-9.

24. Flanigan RC, Russel DP, Walsh JW. Urologic aspect of tethered cord. Urology. 1989;33:80-3.

Submit your manuscript to a SpringerOpen ${ }^{\circ}$ journal and benefit from:

- Convenient online submission

- Rigorous peer review

- Open access: articles freely available online

- High visibility within the field

- Retaining the copyright to your article

Submit your next manuscript at $\boldsymbol{\nabla}$ springeropen.com 